\title{
DER \\ VULGẢRARABISCHE DIALEKT VON JERUSALEM \\ NEBST \\ TEXTEN UND WÖRTERVERZEICHNIS
}

DARGESTELLT

vON

D. DR. MAX LÖHR

A. O. PROFESSOR DER THEOLOGIE IN BRESLAU

सes

ALFRED TÖPELMANN

(VORMALS J. RICKERS VERLAG)

GIESZEN 1905 
